\title{
Morphological and molecular species boundaries in the Hyalella species flock of Lake Titicaca (Crustacea: Amphipoda)
}

\author{
José A. Jurado-Rivera \\ Department of Biology, University of the Balearic Islands, Ctra. Valldemossa, km 7'5, \\ 07122-Palma de Mallorca, Balearic Islands, Spain \\ jose.jurado@uib.es \\ Francesco Zapelloni \\ Department of Biology, University of the Balearic Islands, Ctra. Valldemossa, km 7'5, \\ 07122-Palma de Mallorca, Balearic Islands, Spain
}

Joan Pons

IMEDEA (CSIC-UIB), Mediterranean Institute for Advanced Studies, C/ Miquel Marquès 21, o719o-Esporles, Balearic Islands, Spain

Carlos Juan

Department of Biology, University of the Balearic Islands, Ctra. Valldemossa, km 7'5, 07122-Palma de Mallorca, Balearic Islands, Spain

IMEDEA (CSIC-UIB), Mediterranean Institute for Advanced Studies, C/ Miquel Marquès 21, o719o-Esporles, Balearic Islands, Spain

\section{Damià Jaume}

IMEDEA (CSIC-UIB), Mediterranean Institute for Advanced Studies,C/ Miquel Marquès 21, o719o-Esporles, Balearic Islands, Spain

\begin{abstract}
The Hyalella species diversity in the high-altitude water bodies of the Andean Altiplano is addressed using mitochondrial coxt sequences and implementing different molecular species delimitation criteria. We have recorded the presence of five major genetic lineages in the Altiplano, of which one seems to be exclusive to Lake Titicaca and nearby areas, whereas the rest occur also in other regions of South America. Eleven out of 36 South American entities diagnosed by molecular delimitation criteria in our study are likely endemic to the Titicaca and neighbouring water bodies. We have detected a remarkable disagreement between morphology and genetic data in the Titicacan Hyalella, with occurrence of several cases of the same morpho-species corresponding to several Molecular Operational Taxonomic Units (MOTUs), some even distantly related, and other instances where a particular MOTU is shared by a morphologically

(C) JURADO-RIVERA ET AL., 2020 | DOI:10.1163/18759866-bja10004

This is an open access article distributed under the terms of the CC BY 4.0 license.
\end{abstract}


heterogeneous array of species, including species with body smooth and others with body heavily armoured. Species diversification and incongruence between morphological and molecular boundaries within this species assemblage may be associated to the sharp changes in hydrological conditions experienced by the water bodies of the Altiplano in the past, which included dramatic fluctuations in water level and salinity of Lake Titicaca. Such environmental shifts could have triggered rapid morphological changes and ecological differentiation within the Hyalella assemblage, followed by phenotypic convergence among the diverse lineages. Factors such as phenotypic plasticity, incomplete lineage sorting or admixture between divergent lineages might lie also at the root of the morphological-genetic incongruence described herein.

\section{Keywords}

ancient lakes - Amphipoda - Titicaca - Hyalella - molecular species delimitation

\section{Introduction}

Ancient lakes - those with an uninterrupted history of more than 100,000 years (Gorthner, 1994) - are remarkable by their exceptional species richness compared to other continental water bodies. In such type of lakes, some groups of organisms are prone to occur in the form of large "swarms" of closely related endemic species (Brooks, 1950; Fryer, 1991). For instance, Lake Baikal harbours at least 257 species and 74 subspecies of amphipod crustaceans, all but one being endemic to the lake, representing around $14 \%$ of the known global diversity of freshwater amphipods (Kamaltynov, 1999). Even more remarkable are the ca. 1,000 and 600 endemic species of cichlid fish estimated to live in the East African rift valley lakes Nyasa and Victoria, respectively (Fryer, 2000). How this extraordinary diversity has originated and diversified in a limited space poses fundamental questions on the mechanisms of speciation, community structure and coexistence of closely related species (Cristescu et al., 2010).

A remarkable aspect of these swarms of lacustrine species is the frequent occurrence of a mismatch between species delimited based on DNA sequences and those demarcated following more traditional, morphology-based criteria (Kroll et al., 2012; Naumenko et al., 2017). Such taxonomic decoupling has been recorded to occur also in some of the large radiations of oceanic island terrestrial invertebrates and may be related to the fast speciation rate that concurs on such insular environments (Monaghan et al., 2006; Fryer, 1996; Cristescu et al., 2010). Factors such as genetic introgression, retention of ancient polymorphisms, morphological convergence among distant genetic lineages through selection, or through a combination of selection and hybridization, could be possible causes of the failure of both classical morphological and DNA barcoding approaches to resolve the taxonomy of many of these rapidly radiating lineages (Monaghan et al., 2006). This issue poses a challenge for the species identification and inventorying of the rich biota present in ancient lakes.

Lake Titicaca, at 3,806 $\mathrm{m}$ of altitude, is the only ancient lake present in South America. Although its age has not been precisely determined, it is assumed to date back to between 3 and 2 Million years (Ma) (Kroll et al., 2012). In any event, it is not older than the formation 
of the northern Andean Altiplano where it is located, which has been dated at $5.4 \pm 1.0 \mathrm{Ma}$ (Kar et al., 2016). The Titicaca is placed in a vast endorheic area $\left(\sim 200,000 \mathrm{~km}^{2}\right)$ which harbours also Lake Poopó and the salt flats of Coipasa and Uyuni (fig. 1A, B). Like many other ancient lakes, the Titicaca has a complex palaeo-environmental history (Cristescu et al., 2010). Thus, the different Altiplano basins conformed a single hydrological unit from the Early to Middle Pleistocene (Baker \& Fritz, 2015; Nunnery et al., 2019), when water level experienced at least three major expansions (high stands) of up to 114, 104 and $54 \mathrm{~m}$ above present lake level (Fornari et al., 2001). Furthermore, the lake has passed through several periods of retraction coincident with global interglacial periods, when its level

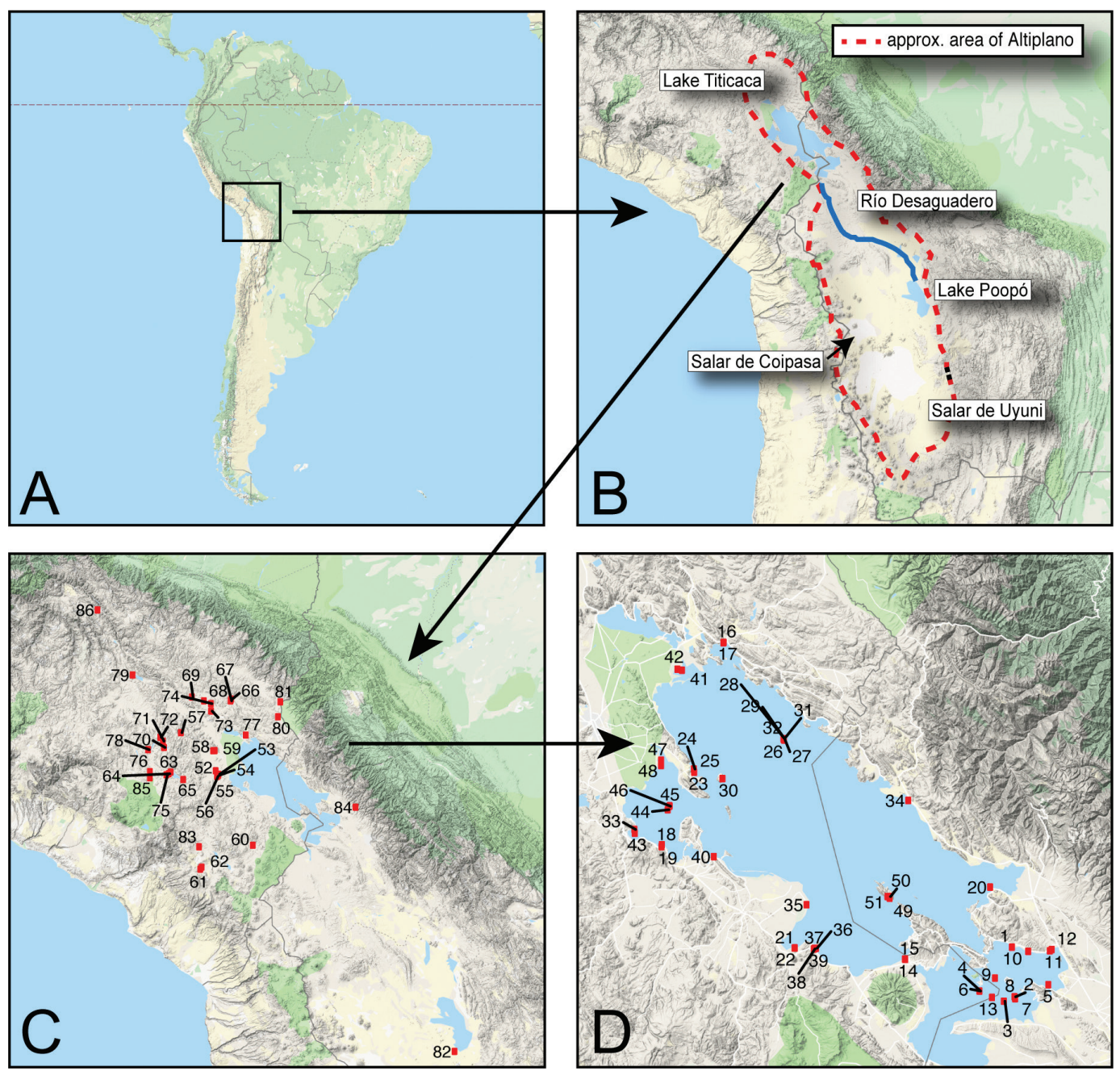

FIGURE 1 A, map of South America showing location of the Andean Altiplano; B, approximate area of the Altiplano showing placement of its main water bodies; C, sampling sites placed outside Lake Titicaca; D, sampling sites at Lake Titicaca itself. Numbers identify sampling stations. See supplementary tables $S_{1}$ and S2 for precise information on sampling sites. Maps were produced using R ggmap (Kahle \& Wickham, 2013) and Google Maps (Google Inc., Mountain View, CA). 
dropped well below its outlet threshold, leading to a closed-basin configuration and an increase in water salinity (Fritz et al., 2012). In the central and southern Altiplano - where Lake Poopó and the salt flats of Coipasa and Uyuni are located -, there is also evidence of the existence of palaeo-lakes at least since the Late Pleistocene. These lakes originated by waters overflowing from the Titicaca basin after the progressive erosion of the threshold between the northern and central Altiplano, a process that was not completed until ca. 6o,000 yr BP (Fritz et al., 2004). In summary, the Altiplano lakes have a complex history of periodical basin connections, disconnections, episodes of desiccation, and abrupt changes in water salinity and depth, all of which may have exerted an important effect on the pattern of species diversification in the area (Nunnery et al., 2019; Fornari et al., 2001).

Lake Titicaca harbours at least 533 species of aquatic organisms, of which only $12 \%$ are endemic to the lake (see Kroll et al., 2012, and references therein). Species flocks have been described in at least three different groups: gastropod molluscs (14 spp. of Heleobia; Kroll et al., 2012; Wolff et al., 2019), cyprinodontid fish (24 spp. of Orestias; Takahashi \& Moreno, 2015) and amphipod crustaceans (at least 18 spp. of Hyalella). Hyalella S. I. Smith, 1874 (Fam. Hyalellidae Bulycheva, 1957) is the only epigean amphipod present in continental waters of South America (Väinölä et al., 2008). The genus occurs only in the Nearctic and Neotropical regions and comprises ca. 76 species thus far (Horton et al., 2019). Eighteen species have been recorded in the Altiplano, of which 15 are endemic to Lake Titicaca (Faxon, 1876; Chevreux, 1904, 1907; Weckel, 1910; González \& Watling, 2001, 2003; González \& Coleman, 2002; Coleman \& González, 2006). Nevertheless, it is probable that this number was only a portion of the actual diversity present in the lake (Dejoux, 1992; Hoffman, 2006;
Crawford et al., 1993; Bousfield, 1996; González \& Watling, 2003). The Hyalella from the Titicaca are morphologically remarkable since several species display the body integument strongly armoured with spines and ridges (fig. 2), an unusual feature rarely reported in non-marine amphipods (see below).

The molecular phylogeny of the Hyalella of Lake Titicaca has been recently studied by Adamowicz et al. (2018) using mitochondrial coxı and nuclear ribosomal $28 \mathrm{~S}$ sequences. They concluded that they are polyphyletic, identifying at least five major distinct evolutionary lineages within the lake, all of them with an age estimated to be much older than the lake itself (20-12 Ma vs. maximum age of the lake 5.4 Ma). Only two of these clades seem to have further diversified by an apparently recent intra-lacustrine diversification (Adamowicz et al., 2018).

In the present study, we bring together DNA-sequence data and morphological observations derived from new material collected at Lake Titicaca and its main satellite lakes, plus at many other high-altitude water bodies of the Altiplano (see fig. 1 ) to explore the $H y$ alella species diversity and their diversification pattern. Expanding the sampling scheme to cover as many localities as possible around the Titicaca is crucial to elucidate the modes of diversification of its amphipod species flock since many of these high-altitude lakes were captured by the Titicaca in former periods of high-water level (see above). We make use of an extensive coxı dataset resulting from merging our sequences to the ones available in BOLD (www.boldsystems.org) to explore the Hyalella species diversity in the Altiplano using mPTP, GMYC and ABGD species delimitation criteria. The species delimitation proposals are contrasted with the morphological variation displayed by Titicacan Hyalella, exploring the following questions: (1) have the armoured bodies of some Hyalella species 
evolved only once or did they arise independently in several Titicacan lineages? (2) how congruent are the different molecular delimitation methods implemented and how do they relate to the morphospecies known to occur in the Andean Altiplano? Our study also aims to build a genetic reference coxı library as a platform to be used in future morphological and evolutionary studies of this amphipod lineage endemic to an ecologically complex, ancient lake system.

\section{Material and methods}

\section{Samples}

We collected Hyalella specimens at 51 different sites in Lake Titicaca and at 35 sites from 30 additional water bodies of the Altiplano and nearby areas of Perú and Bolivia (see fig. ${ }_{1} \mathrm{C}, \mathrm{D}$, and supplementary tables $\mathrm{S}_{1}$ and $\mathrm{S}_{2}$ for the location of sampling sites and composition of the Hyalella assemblage per site). Furthermore, we used also three samples of $H$. cajasi Alonso \& Jaume, 2017, from southern Ecuador (collected at high-altitude lakes of El Cajas Massif; Azuay), and one of $H$. franciscae González \& Watling, 2003, from southernmost Chile (Madre de Dios Island; Magallanes Region), all of them out of the study area. Specimens were collected directly with hand-held plankton nets or with a small dredge thrown either from the shore of the lake or from a boat, and preserved in 96\% ethanol. Individuals were first sorted out and identified based on morphological characters and classified as "morphospecies". To explore the correspondence between morphospecies and Molecular Operational Taxonomic Units (MOTUs) we used ten taxa easily and unambiguously diagnosable based on morphology (see below for a key to all Hyalella species from Lake Titicaca and other water bodies of the Altiplano area). Unfortunately, we failed to collect any representative of the species triplet $H$. echinus/ crawfordi/ gauthieri, easily distinguishable by the common display of combined midline and lateral armature on body tergites (see Coleman \& González, 2006). The species $H$. tiwanaku, $H$. kochi and $H$. cuprea are likely to include hidden diversity and were used only as a preliminary morphospecies reference. The species considered were as follows: $H$. longipes (eleven spines on dorsal midline; fig. $2 \mathrm{~K}$ ); H. neveulemairei (six spines on dorsal midline; fig. $2 \mathrm{~F}$ ); H. longipalma (five spines on dorsal midline, one on each pereionites 6-7 and pleonites $1-3$, respectively; fig. $2 \mathrm{~B}$ ); $\mathrm{H}$. sol$i d a$ (also five spines on dorsal midline, but this time one on each pereionites $5^{-7}$ and pleonites $1-2$, respectively; fig. $2 \mathrm{~A}$ ); $H$. armata (one spine laterally-directed on each pereiopodal coxal plates 1-4; fig. 2G, H); H. knickerbockeri (two spines on dorsal midline, one on each pleonites 1-2, respectively; fig. 2I); Hyalella n. sp. 1 (body smooth, compact, with shortened antennules and antennae; fig. 2J); Hyalella $\mathrm{n}$. sp. 2 (body smooth, with medial margin of merus and carpus of pereiopods 3-4 fringed with long setae); $H$. nefrens (three spines on dorsal midline, one on each pereionite 7 and pleonites 1-2, respectively, and mandible incisor smooth); H. montforti (four dorsal spines, one on each pereionite 7 and pleonites $1-3$, respectively, and with male first uropod with a modified spine on endopod; fig. $2 \mathrm{C}$ ); and $H$. latimanus (also with four dorsal spines as $H$. montforti, but with male first uropod lacking modified spine on endopod).

\section{Molecular procedures}

Genomic DNA was individually purified from whole specimens using the Qiagen DNeasy Blood \& Tissue kit (Qiagen, Hilden, Germany) following the manufacturer protocol. Voucher specimens and DNA aliquots are deposited at the Instituto Mediterráneo de Estudios Avanzados (IMEDEA, Spain). A total of 

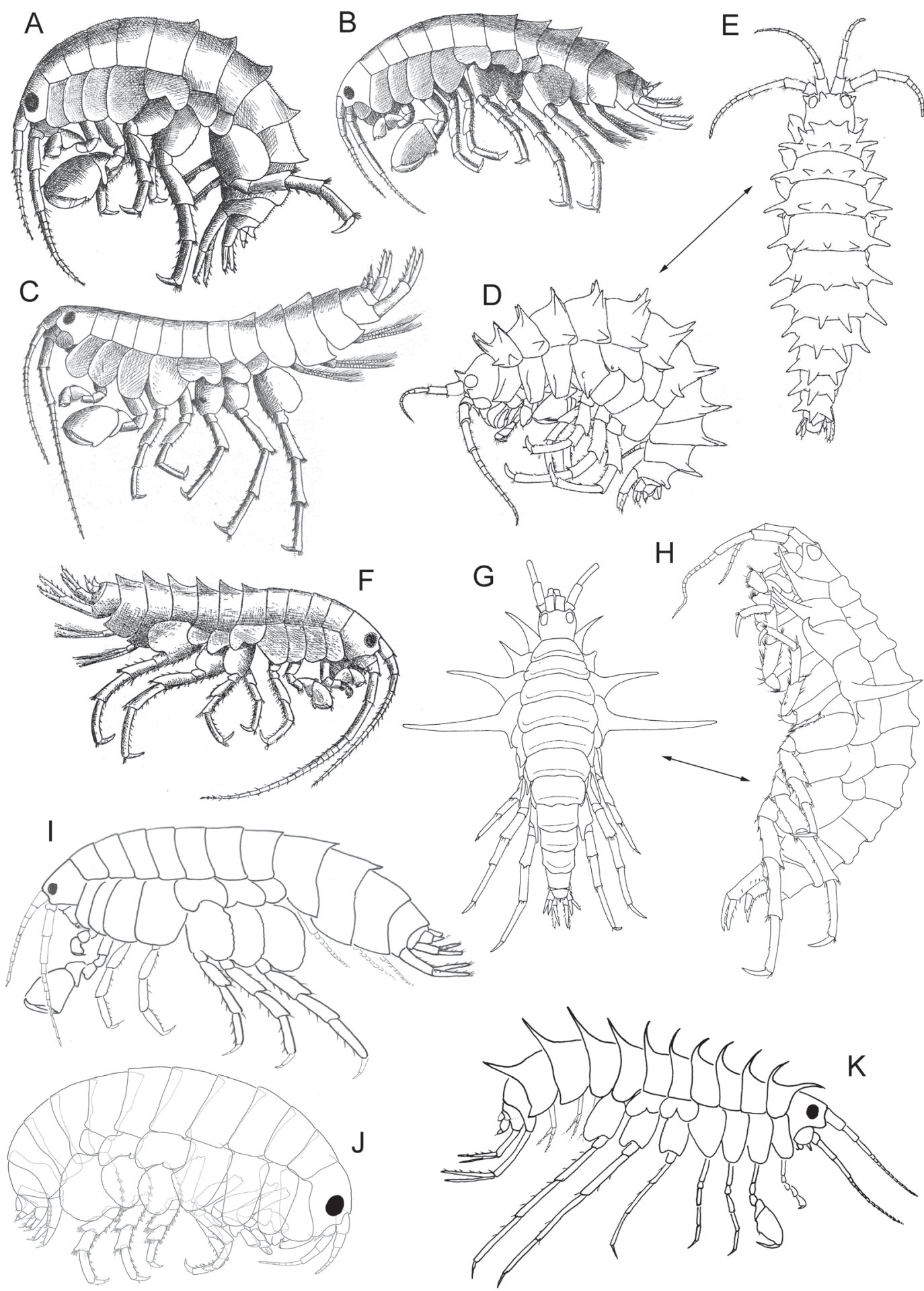

FIGURE 2 Morphological disparity within the Hyalella species-flock of Lake Titicaca. A, H. robusta; B, H. longipalma; C, H. montforti; D-E, H. crawfordi; F, H. neveulemairei; G-H, H. armata; I, H. knickerbockeri; J, Hyalella n. sp. $1 ; \mathrm{K}$, H. lucifugax. See key to species for description of precise armature arrangement on each species. [A-C, E: after Chevreux (1907); D, E: after Coleman \& González (2006); G, H: after

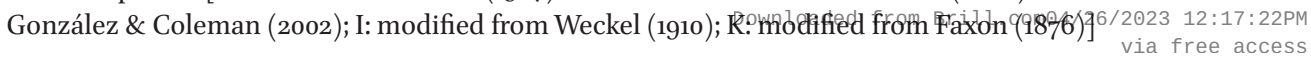


197 specimens were sequenced for a fragment of themitochondrialcytochromecoxidasesubunit 1 gene ( $\left.c o x_{1}\right)$ using the primer-pair LCO/ HCO (Folmer et al., 1994), and a subset consisting of 69 individuals for a fragment of the nuclear gene Histone $\mathrm{H}_{3}$ using the primer pair HzaF/HzaR (Colgan et al., 1998) (GenBank accession numbers $\mathrm{MN}_{582154}$ - $\mathrm{MN}_{582350}$ and $\mathrm{MN}_{582351}$ - MN582419, respectively; see supplementary table $S_{3}$ ). The coxı sequences obtained were distributed as follows: 183 individuals from the Titicaca and nearby areas in Perú and Bolivia, 13 from Ecuador and one from Chile (see fig. 1C, D, and supplementary tables $S_{1}$ and $S_{2}$ for details on sampling sites). For phylogenetic and species delimitation analyses our sequence data set was merged with the coxr sequences of South American Hyalella available at the BOLD database (http://www.boldsystems.org; project "TTKK"; included partially in the study of Adamowicz et al., 2018). The resulting dataset represents an extensive South American $\mathrm{Hy}$ alella cox 1 repository of 1,139 sequences from Perú and Bolivia (mostly collected at Lake Titicaca and areas nearby), 122 from Argentina, 65 from Chile and 13 from Ecuador. Sanger sequencing followed standard protocols described elsewhere (Bauzà-Ribot et al., 2011). Sequences were filtered using the Perl script uniqHaplo.pl (Takebayashi, 2015), retaining unique haplotypes for subsequent analyses. The resulting dataset consisted of 560 Hyalella coxı sequences and was used for subsequent phylogenetic and species delimitation analyses. The histone $\mathrm{H}_{3} \mathrm{~A}$ sequences rendered only nine haplotypes with a total of 23 parsimony-informative nucleotide positions and a remarkably low phylogenetic signal (see results).

\section{Phylogenetic analyses}

The 560 cox 1 mitochondrial DNA sequences were trimmed to start and end with complete triplets, aligned at the amino acid level using
MAFFT 7 (Katoh \& Standley, 2013) in SeaView (Gouy et al., 2009) to inspect for the absence of indels and stop codons, and finally backtranslated to nucleotides preserving the alignment by codons, resulting in final nucleotide alignment of $648 \mathrm{bp}$. Histone $\mathrm{H}_{3}$ sequence alignment was also performed with $\mathrm{MAFFT}_{7}$ using the default FFT-NS-1 algorithm. As no robust support for a reciprocal monophyletic relationship of North and South American $\mathrm{Hy}$ alella was obtained in preliminary analyses, seven Platorchestia spp. coxı sequences retrieved from GenBank (accession numbers KC578469, KC578473, KC578478, KC578488 and $\mathrm{KC}_{578494} \mathrm{KC}_{578495}, \mathrm{MG}_{936436)}$ were used as outgroup in the mitochondrial phylogenetic analyses. Coxı phylogenetic trees were built under a maximum likelihood (ML) framework in IQ-TREE (Nguyen et al., 2014) and under Bayesian analyses with BEAST v1.8.4 (Drummond \& Rambaut, 2007). The best partition schemes and models were explored in PartitionFinder (Lanfear et al., 2012). The optimal partitioning strategy and evolutionary models consisted of subdividing the coxt data set by codon positions with the models $\mathrm{TRN}+\mathrm{I}+\mathrm{G}, \mathrm{GTR}+\mathrm{G}$ and $\mathrm{GTR}+\mathrm{I}+\mathrm{G}$, respectively. For Bayesian analyses, best partition schemes, two different molecular clock (strict and lognormal-relaxed) and two diversification models (constant size coalescent and Yule speciation process) were compared using Bayes Factors based on marginal likelihood estimations through path sampling and steppingstone calculations in BEAST (Baele et al., 2012). The optimal scheme consisted in partitioning the data by codon sites, and the specification of a lognormal-relaxed clock with constant size coalescence tree model (supplementary table $\mathrm{S}_{4}$ ). Analyses with the optimal scheme consisted of four independent runs of 200 million generations each. MCMC chain convergence and the burnin fraction (10\%) was assessed in Tracer v1.7 ensuring parameter values to have ESS values $>200$. 


\section{Molecular species delimitation}

Species were first delimited based on the ingroup 56o coxt unique haplotypes using genetic distances in Automatic Barcode Gap Discovery (ABGD; Puillandre et al., 2012). This approach finds recursively the slope above a cut-off value that splits the data in intra- and interspecific distances starting from an arbitrary minimum $(\mathrm{p})$ and maximum $(\mathrm{P})$ values. We used the default value $\mathrm{p}=\mathbf{0 . 0 0 1}$, enabling the existence of nearly identical haplotypes and $\mathrm{P}=0.1$ after the maximum intraspecific distance previously found in a densely sampled amphipod species (Bauzà-Ribot et al., 2011). Distances were calculated using the $\mathrm{K}_{2} \mathrm{P}$ nucleotide substitution model with a lower cut-off value $(X=1.0)$. These values were used to estimate the minimum optimal gap between intra- and interspecific distances. Species boundaries and their support were also estimated with the Multi-rate Poisson Tree Processes method (mPTP), a method that fits the branching events of each delimited species to a distinct exponential distribution and does not require of any similarity threshold as input (Kapli et al., 2017). This analysis was performed based on the obtained rooted ML IQTREE phylogenetic tree after removing the outgroups and using two independent MCMC chains at 100,000,000 generations each with a sampling frequency of 1,000.

Finally, the Generalized Mixed Yule Coalescent model (GMYC; Pons et al., 2006; Fujisawa \& Barraclough, 2013) was also used to delimitate species. This method applies a likelihood ratio test to compare a single coalescent branching rate across a clock-like tree as a null hypothesis with a model including both coalescent and Yule branching treebifurcating patterns. The R library SPLITS v1.o19 (Ezard et al., 2009) was used for this analysis, specifying a single threshold on the ultrametric tree estimated with BEAST v1.8.4 as described above. The GMYC support value of each node representing a transition from species to population was calculated as the sum of Akaike weights of candidate delimitation models where the node is included (Fujisawa \& Barraclough, 2013). A node support value of 1 means that all models tested point to the occurrence of a speciation event at that node, while lower values indicate that fewer support for it. We set an arbitrary minimum value of 0.9 to consider a GMYC entity as supported by most coalescent models.

\section{Results}

\section{Mitochondrial phylogeny}

Both ML and Bayesian coxı trees showed consistent topologies and yielded seven monophyletic clades with high bootstrap and posterior probability support values (called A to $G$ from now onwards), although their inter-clade phylogenetic relationships are not well resolved with this mitochondrial marker (fig. 3 and supplementary figs $\mathrm{S}_{1}$ and $\mathrm{S}_{2}$ ). The Histone $\mathrm{H}_{3}$ tree topology obtained from a reduced number of the sampled individuals was less informative than the mitochondrial one but pointed to the presence of the same major clades (supple mentary fig $\mathrm{S}_{3}$ ). Five of these clades include taxa present in the Andean Altiplano (Adamowicz et al., 2018). Members of clade D occur only at Lake Titicaca and surrounding riverine and lagoon habitats of the Altiplano, whereas clades A, B, C and E display a much broader South American distribution, encompassing Argentina and Chile aside the Altiplano of Perú and Bolivia (see supplementary table $\mathrm{S}_{5}$, fig. 3 and supplementary fig S1). Clades F and G include only taxa from Ecuador and Argentina, respectively.

\section{Species molecular delimitation and geographic distribution}

The ABGD method identified a total of 30 MOTUs in the pool of South American Hyalella. The application of the MPTP method 


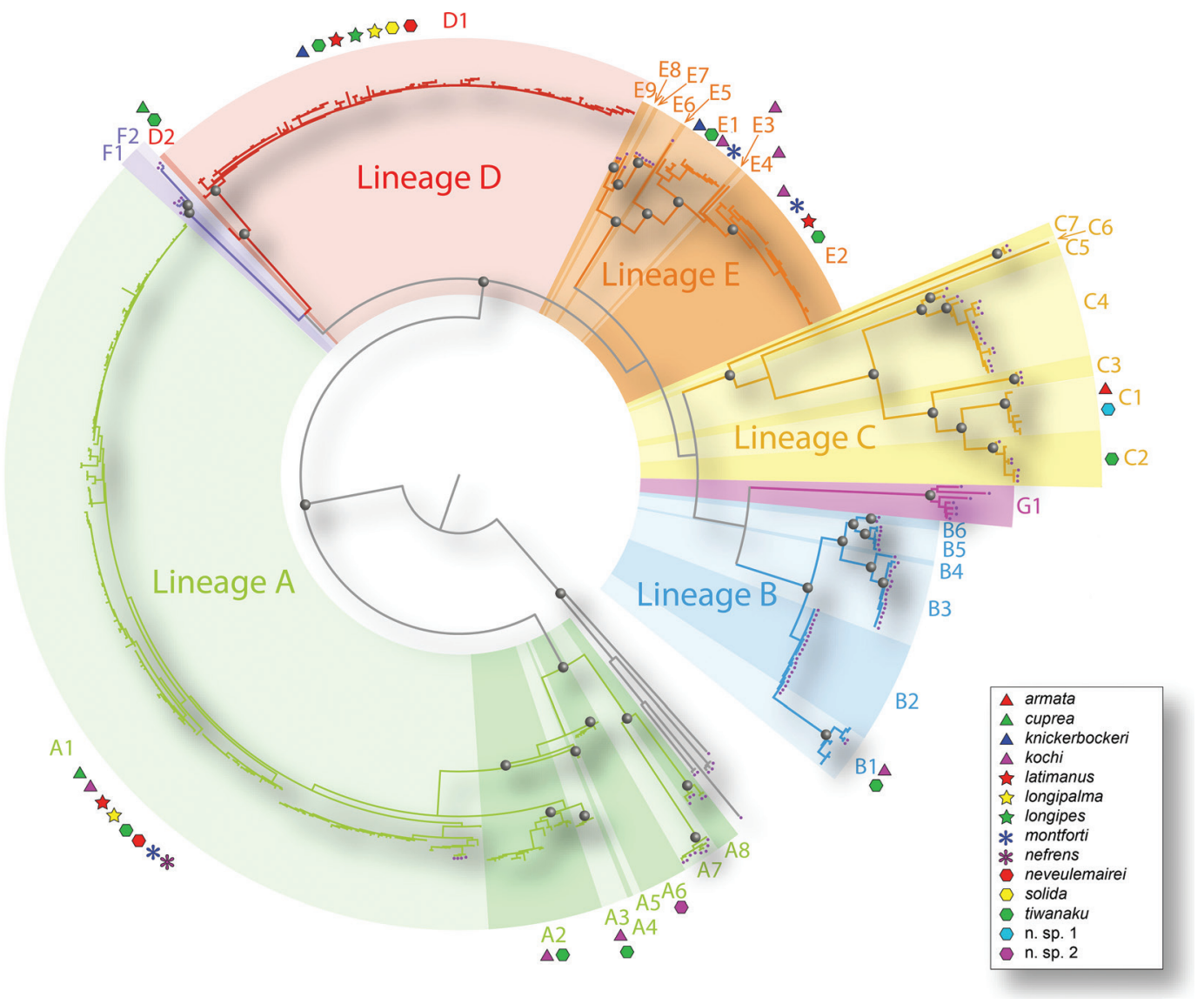

FIGURE 3 Bayesian phylogeny and molecular species delimitation of South American Hyalella based on currently available coxı mitochondrial data (present work and Barcode of Life DATA Systems (BOLD) repository project TTKK). Nodes with maximum nodal support are remarked with circles. Purple dots on branch tips indicate haplotypes exclusively sampled in South America outside the Altiplano area (see supplementary fig S1 for details). See main text for details on molecular species delimitation methods and results.

delimited 34 molecular entities as possible species, a number that scaled up to 56 using the GMYC algorithm, applying the rigorous option of considering only entities supported by more than $90 \%$ of the tested models. We decided to follow a conservative species delimitation scheme based on (1) consensus of the three species delimitation methods, (2) posterior probability support values of each putative species, and (3) reciprocal monophyly in the phylogenetic tree. This reduced the number of molecular entities to 36 (figs. 3 and 4; supplementary fig $\mathrm{S}_{1}$ ) that showed a mean intergroup $\mathrm{K}_{2} \mathrm{P}$ distance of
$0.171(\mathrm{SD}=0.041)$ and an intragroup (MOTU) distance of $0.011(\mathrm{SD}=0.008)$ (supplementary table S6).

Eight out of the 36 MOTUs identified in the analyses belong to clade $\mathrm{A}$, of which all but two (MOTUs A7 and A8, limited to occur in Argentina) are circumscribed to the Titicaca and/or the Altiplano area, although some members of MOTU A1, broadly distributed across the Altiplano, occur also in the nearby Atacama region of Chile (fig. 3 and supplementary fig $\mathrm{S}$ ). Clade B includes six MOTUs, of which only the putative species $\mathrm{B} 1$ is limited to occur in the target study area 


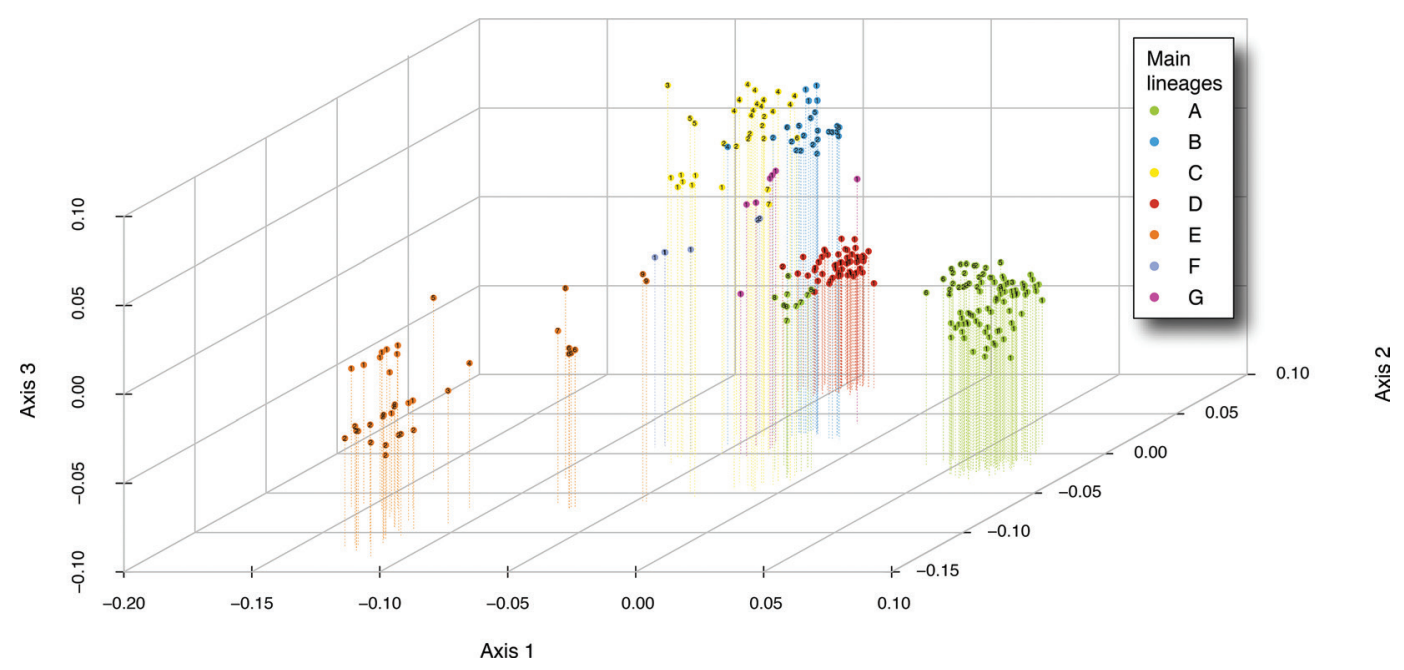

FIGURE 4 Multidimensional scaling plot based on Kimura 2-parameters genetic distances of the 560 unique coxt haplotypes detected in Hyalella. Dot colours refer to the main Hyalella lineages inferred in the molecular species delimitation analyses. Dots have been numbered according to their MOTU assignment.

(Titicaca + Altiplano area + the Atacama Desert area of Chile) (fig. 3, supplementary fig S1 and supplementary table $S_{5}$ ). Out of the seven MOTUs included in clade $\mathrm{C}$, only species $\mathrm{C} 1$ occurs exclusively in Lake Titicaca whereas species $\mathrm{C}_{2}$ inhabits in both Atacama (Chile) and several lagoons of the Altiplano. The rest of species in this group dwell in Argentina and Chile (fig. 3 and supplementary fig $\mathrm{S} 1$ ). Clade D comprises only two putative species defined by molecular methods, of which one (molecular entity D1) has a broad distribution across the Altiplano including the Titicaca, and the second (D2) is represented by a single specimen collected at the extra-limital Lake Langui-Layo beside the northern border of the Peruvian Altiplano (station no. 79 in fig. $1 \mathrm{C}$ ) (fig. 3 and supplementary fig $\mathrm{S} 1$ ). Finally, Clade E includes nine MOTUs, of which only four occur exclusively in the Titicaca and/or Altiplano area, with one (E5) recorded also in the neighbouring Atacama region; the rest of species in this clade occurs only in Argentina (fig. 3 and supplementary fig $\mathrm{S}_{1}$ ).

\section{Incongruence between morphological and molecular species boundaries}

The mitochondrial lineages of Hyalella recognized in the Altiplano show largely overlapping geographical ranges and a considerable lack of congruence with morphological species delineations (fig. 1 and table 1 ). We assigned the individuals collected in the area to at least twelve already described and two previously unknown morphospecies (table 1). Two of these taxa show a broad distribution across the Altiplano and share a smooth, nonprocessiferous body, namely $H$. kochi and H. tiwanaku; each one of these species might represent a species complex and will not be considered further in the analyses (table 1). Our results also show that (1) all clades but B include species with a processiferous body (figs. 3 and 4); (2) occurrence of incomplete lineage sorting of mitochondrial haplotypes of morphospecies is widespread across the phylogeny; and (3) many cases of well-defined species based on morphology are in conflict with mitochondrial DNA lineages (see table 1 
TABLE 1 Distribution of the Hyalella morpho-species of the Titicaca/Altiplano across the different MOTUs delimited in the analyses

\begin{tabular}{|c|c|c|c|c|c|c|c|c|c|c|c|c|c|c|}
\hline & A1 & A2 & A3 & A6 & B1 & $\mathrm{Cr}$ & $\mathrm{C}_{2}$ & D1 & D2 & E1 & E2 & $\mathrm{E}_{3}$ & $\mathrm{E}_{4}$ & Armoured body \\
\hline armata & & & & & & + & & & & & & & & yes \\
\hline cuprea & + & & & & & & & & + & & & & & no \\
\hline knickerbockeri & & & & & & & & + & & + & & & & yes \\
\hline kochi & + & + & + & & + & & & & & + & + & + & + & no \\
\hline latimanus & + & & & & & & & + & & & + & & & yes \\
\hline longipalma & + & & & & & & & + & & & & & & yes \\
\hline longipes & & & & & & & & + & & & & & & yes \\
\hline montforti & + & & & & & & & & & + & + & & & yes \\
\hline nefrens & + & & & & & & & & & & & & & yes \\
\hline neveulemairei & + & & & & & & & + & & & & & & yes \\
\hline solida & & & & & & & & + & & & & & & yes \\
\hline tiwanaku & + & + & + & & + & & + & + & + & + & + & & & no \\
\hline n. sp. 1 & & & & & & + & & & & & & & & no \\
\hline n. sp. 2 & & & & + & & & & & & & & & & no \\
\hline
\end{tabular}

and supplementary fig $\left.\mathrm{S}_{1}\right)$. For instance, the morphospecies $H$. knickerbockeri, $H$. latimanus, H. longipalma, $H$. montforti, $H$. nefrens or $H$. neveulemairei - each easily identifiable on the basis of the display of a precise pattern of integumentary ornamentation (see key to species below) - all include A1 mitochondrial haplotypes, but some of them also haplotypes from genetically distant clades (e.g., D1, case of $H$. longipalma and $H$. neveulemairei; $\mathrm{D} 1$ and E2 in H. latimanus; E1 and E2 in H. montforti) (table 1). Only three morphospecies display a single MOTU each, viz. H. armata and Hyalella n. sp.1, which share the same MOTU C1, and Hyalella n. sp. 2, which displays MOTU A6 (see table 1).

In summary, eleven out of the South American mitochondrial entities diagnosed by molecular methods in the present study appear as endemic to the Titicaca + Altiplano area (MOTUs A2-A6, C1, D1-D2, E2-E4) whereas another four seem to have expanded their range to outside the boundaries of the Altiplano (A1, $\mathrm{B} 1, \mathrm{C} 2, \mathrm{E} 1)$, in particular to the Atacama Desert in Chile. Clades A and E are the most diversified at this high-altitude territory, including six and four genetically differentiated MOTUs, respectively.

\section{Discussion}

Our coxi sequences coalesced in most cases with those of Adamowicz et al. (2018) data set, except for the mitochondrially delimited putative species $\mathrm{E}_{3}, \mathrm{E}_{4}$ and $\mathrm{D}_{2}$ from the Peruvian Altiplano lagunas Orurillo, Súchez, and Langui-Layo, respectively (stations 69, 81 and 79 in fig. $1 \mathrm{C}$ ). The connection between populations in the Altiplano and the Atacama Desert in Chile put forward repeatedly in our analysis might suggest a possible role of shorebirds in the dispersal of Hyalella species across the area (Rosine, 1956; Daborn, 1976; Swanson, 1984). Adamowicz et al. (2018) used Barcode Index Numbers (BINs), a method that implements a species threshold value of $2 \%$, to detect 48 BINs among their South American Hyalella data set, twelve of them occurring at the Titicaca area including six uniquely sampled in the lake itself. However, studies in marine amphipods using different barcode gap 
detection techniques have concluded that a single threshold may be unsuitable to delimitate species in this order of crustaceans and could even be misleading (Costa et al., 2007, 2009; Tempestini et al., 2018; Jażdżewska \& Mamos, 2019). Furthermore, the use of a single threshold for species delimitation can be particularly problematic in island and islandlike rapid radiating lineages (Monaghan et al., 2006). In our case, the results of the three different species delineation methods -two of them based on gene trees and one on distance matrices- differed in the number of species diagnosed in the South American Hyalella sample, with GMYC arising as the method delimiting the highest number of molecular entities. The ABGD approach produced the lowest estimate of diversity rendering a total of 30 molecular entities. The Generalized Mixed Yule Coalescent model has been shown to be useful in detecting incipient speciation events, where both intra- and interspecific distances are expected to be low, but it is known to frequently overestimate species numbers (Hendrich et al., 2010, Talavera et al., 2013, Kekkonen et al., 2015). It has been suggested that assessing the uncertainties in tree topology and the support obtained by different coalescent models in GMYC can lead to a more robust estimation of species numbers (Talavera et al., 2013, Fujisawa \& Barraclough, 2013). Indeed, our Hyalella mitochondrial tree shows relatively long inter-clade but shallow within-clade branches, which is consistent with a scenario of recent diversification and the idea of "ecological opportunity" (Wagner et al., 2012). This applies in particular to clades A, D and E, that are the ones that more likely derive from incipient intra-lacustrine diversification (fig. 3 and supplementary fig $\mathrm{S} 1$ ). GMYC clearly over-splits the number of entities present in clade $\mathrm{A}$, where twenty-one MOTUs were identified by this method, while ABGD and mPTP diagnosed only three and eight, respectively (supplementary fig S1). Therefore, it is preferable to apply different methodologies and to check for their congruence (Carstens et al., 2013). The Multi-rate Poisson Tree Processes method (mPTP) may be particularly well suited to our Hyalella dataset since it assumes the sampled species show different levels of intraspecific genetic diversity, arising either from differences in their evolutionary history or the uneven sampling of each taxon (Kapli et al., 2017). This method predicted the occurrence of 34 molecular entities in our sampling. We applied a conservative approach (see methods) to conclude that at least 36 molecular entities can be diagnosed in the South American Hyalella dataset, eleven of them occurring exclusively in the Andean Altiplano.

An assessment of the Hyalella species diversity present in our samples based on morphological criteria pointed to the presence of a minimum of twelve known described species and two presumably new (table 1 and supplementary tables $S_{1}$ and $S_{2}$ ). Our results clearly show that mitochondrial sequence phylogenetic relationships are largely at odds with suggested species delineations based on morphological features, as a single MOTU, or even haplotype, is often shared by a heterogeneous array of morphospecies (see table 1). For instance, MOTU C1 is shared by H. armata (a species characterised by the display of a long transverse spine on each pereiopodal coxal plates 1-4; fig. 2G, H) and Hyalella n. sp. 1 (a species devoid of any body armature and characterised by its compact body and shortened antennules and antennae; fig. 2J; see also key to species below); MOTU D1 is present in all the species with 5, 6 or 11 dorsal spines, aside of several species devoid of integumentary armature. Only the nominal species $H$. longipes, $H$. solida, $H$. nefrens and Hyalella n. sp. 2 display coxı sequences falling in a single clade and MOTU (although all 
except the latter species share their respective MOTU with other morphospecies; see Results and table 1). In other instances (e.g., $H$. neveulemairei; $H$. longipalma; $H$. latimanus) the same morphospecies includes MOTUs falling in several of the five main clades present in the Altiplano. The widespread discordance between molecular and morphological divergence suggests an evolutionary scenario of rapid morphological and ecological differentiation accompanied by phenotypic convergence within the different lineages, a pattern common to other ancient lake radiations such as those of the cichlid fishes of the East African lakes (e.g., Meyer et al., 1990; Kocher, 2004) and the amphipod assemblage of Lake Baikal (Macdonald et al., 2005; Naumenko et al., 2017). Although the age and geological history of Lake Titicaca and Lake Baikal are notably different - as are the level of taxonomic diversity and the ancestral colonizing lineages in their respective amphipod assemblages -, a common pattern arises. It includes the remarkable level of morphological disparity attained in both amphipod assemblages; the episodic development of spiny morphologies; the presence of morphologically well-differentiated species that are hardly differentiated genetically (e.g., Parapallasea spp. and Oxyacanthus spp. at Lake Baikal) and the occurrence of cases of cryptic differentiation (e.g., Eulimnogammarus cruentus at Lake Baikal; Naumenko et al., 2017).

The phylogeny obtained shows that armoured spiny morphologies have evolved independently multiple times in the Altiplano, since they appear in all but one of the clades. Spiny morphologies are frequent among members of typical amphipod marine families such as the Iphimediidae Boeck, 1871, Dexaminidae Leach, 1814 and the Atylidae Lilljeborg, 1865 , but occurs rarely among epigean continental water forms. Only some members of the Lake Baikal species-flock (Takhteev, 2000, 2019), several Caspian gammaroids (Sars, 1894, 1896), and the monotypic genus Fuxiana Sket, 2000 from Lake Fuxian (another ancient lake, from Yunnan, China; Sket, 2000) share with the Hyalella from the Titicaca a comparable integumentary ornamentation. Spiny morphologies have evolved independently in amphipods of Lake Baikal at least in four occasions, with at least two cases recorded of reversal to non-spiny forms (Naumenko et al., 2017). Interestingly, spinose and heavily calcified shells are also frequent among the endemic gastropods of ancient lake Tanganika, where these morphologies have appeared convergently several times. As in the case of the amphipod species flocks present in some ancient lakes, spinose shells occur frequently in marine gastropods but not in freshwater ones, a fact that has been interpreted as defensive adaptations against predators in a coevolutionary arms race scenario (Vermeij and Covich, 1978; West and Cohen, 1996). In the Titicaca, the development of this armature might be related to the predation pressure exerted by the cyprinodontid killifish endemic to the lake (Orestias Valenciennes, 1839; up to 24 spp; Lauzanne, 1992; González \& Coleman, 2002), similarly as it has been demonstrated for the amphipods Gammarus pulex and G. roeselii (Bollache et al., 2005; Copilas-Ciocianu et al., 2020). In the latter case, an extreme variation in both the number and shape of spines has been reported despite the little inter-populational coxt differentiation, a scenario attributed to the combination of fish predation with either phenotypic plasticity or local adaptation (Copilas-Ciocianu et al., 2020).

Both our results and those of Adamowicz et al. (2018) clearly show that Lake Titicaca has been colonized by multiple South American Hyalella lineages, raising the possibility that hybridization between some of them 
resulted in an increase in diversification rates as has been demonstrated in the cichlid fishes of several African lakes (see below). Adamowicz et al. (2018) found a general concordance between mitochondrial coxı and ribosomal rRNA gene (28S) phylogenies in the Titicacan Hyalella, with only one case of presumed occurrence of unidirectional hybridization. Unfortunately, our limited Histone 3 nuclear gene sequence dataset rendered a low phylogenetic signal, impeding to address a detailed analysis of the congruence between nuclear and mitochondrial gene trees. Cytonuclear discrepancies and complex relations with morphological variation are frequent issues among the cichlid fishes of the East African lakes Malawi, Tanganyika and Mweru (Egger et al., 2007; Nevado et al., 2009; Koblmüller et al., 2017; Meier et al., 2019). The origin of such discrepancies has been related to the occurrence of secondary contacts linked to lake level fluctuations among the differentiated lineages, followed by introgression or to the occurrence of incomplete lineage sorting (Koblmüller et al., 2017).

Lake Titicaca and other water bodies of the Andean Altiplano have experienced drastic changes in hydrological conditions during the geological past. Thus, retraction or even extinction of lacustrine populations might have been triggered by the increase in water salinity associated to the establishment of low water stands in the Titicaca basin. These occurred as recently as between $8,000-3,600 \mathrm{yr}$ $\mathrm{BP}$, when the water level receded $90 \mathrm{~m}$ below its present level, and especially during a period that ended up at 90,00o yr BP, when it dropped $240 \mathrm{~m}$. During the latter period, the lake volume decreased by $80 \%$ and its extension and depth attained only $2,000 \mathrm{~km}^{2}$ and 40 $\mathrm{m}$, respectively (D'Agostino et al., 2002). For a closed-basin interval of 9,500 years just before 2,000 yr BP, Cross et al. (2001) estimated that the maximum salinity of the lake should have increased to about half the seawater value. Although some Hyalella have been reported to thrive in waters up to $37 \%$ in salinity in some Canadian athalasohaline lakes (Hammer et al., 1990), the genus is mostly found at water salinities below $8 \%$ (Colburn, 1988; Galat et al., 1988; Alcocer et al., 1998). In the Altiplano area, Hyalella has not been recorded at water salinities above $2.4 \%$ (pers. obs.; Dejoux, 1993). During these past stressing periods, $H y$ alella might have found temporal refuge in those sectors of the Titicaca where salinity remained low due to river or groundwater discharge, or even in the assemblage of lakes and rivers of the Altiplano area, which offer plenty of opportunities to population subdivision and recolonization, enabling also the hybridization between different lineages. These episodes may have played a major role in the diversification of the Hyalella across this vast high-altitude area.

The present study examined Hyalella mitochondrial sequences distributed across Lake Titicaca and other water bodies of the Andean Altiplano. We confirmed previous results of Adamowicz et al. (2018) on the occurrence of five major monophyletic clades there, and delimited conservatively fifteen mitochondrial molecular entities within this assemblage, although they appear mostly in conflict with the morphospecies recorded in the area, which are not resolved as monophyletic groups in our cladogram. The mitochondrial genetic diversity present in the studied sequences reveals Altiplano amphipods have a complex evolutionary history that needs robust nuclear and mitochondrial phylogenetic hypotheses to explore in deeper detail which factors may have contributed to their evolutionary history. This may be achieved via the analysis of high-resolution genomic data such as complete mitochondrial genomes, orthologous nuclear genes, and Single Nucleotide Polymorphisms. 
Key to the Hyalella species from Lake Titicaca and the Altiplano area

(Abbreviations: A1, antennule; A2, antenna; G2, gnathopod II; P1-7, pereionites I-VII; PL1-3, pleonites I-III; U1, uropod I)

1. Mandible incisor smooth..........H. nefrens González \& Watling, 2003

Incisor dentate 2.

2. Body processiferous 3.

- $\quad$ Body smooth 8.

3. Armature developed only on midline of body tergites. 4 .

- Armature developed on both midline and lateral margins of body tergites....12. Armature developed only on pereiopodal coxal plates I-IV .14 .

4. Body with 2 dorsal spines (one on each pleonite I-II)....."H. knickerbockeri” sensu Weckel, 1910

Body with 4 dorsal spines or flanges (on $\mathrm{P}_{7+\mathrm{PL1}}$-3). 5 .

Body with 5 dorsal spines or flanges .... 6 . Body with 6 dorsal spines (one on each

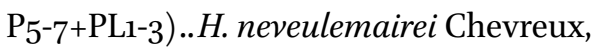
1904

Body with 11 dorsal spines (two on $\mathrm{P} 1$; one on each P6-7+PL1-3)........................... 7 .

5. Male U1 ordinary ... H. latimanus (Faxon, 1876)

- Male U1 with modified spine on endopod. H. montforti Chevreux, 1907

6. Dorsal flanges on $\mathrm{P}_{5-7}+\mathrm{PL1}_{1-2}$

H. solida Chevreux, 1907

Dorsal spines on P6-7+PL1-3

H. longipalma (Faxon, 1876)

7. First 5 dorsal spines short and directed backward. H. longipes (Faxon, 1876)

- $\quad$ First 5 dorsal spines long and procurved H. lucifugax (Faxon, 1876)

8. Medial margin of merus and carpus of pereiopods III-IV fringed with long setae Hyalella n. sp. 2
Medial margin of merus and carpus of pereiopods III-IV ordinary, armed with short spines ...9.

9. Male U1 with modified spine on endopod. H. kochi González \& Watling, 2001

- $\quad$ Male U1 ordinary .10.

10. A1 \& A2 shortened, hardly longer than head. Hyalella n. sp. 1

A1 \& A2 much longer than head

11. Male G2 propodus with posterior margin longer than palm margin.

H. tiwanaku González \& Watling, 2003

Male G2 propodus with posterior margin much shorter than palm margin ........ H. cuprea (Faxon, 1876)

12. Pereionites II-VII each with 3 dorsal and 2 lateral processes. H. crawfordi Coleman \& González, 2006

Pereionites II-VII each with 2 dorsal and 2 lateral processes. 13.

13. Pleonites I-III each with 2 dorsal processes only. H. echinus (Faxon, 1876)

Pleonites I-III each with 2 dorsal and 2 lateral processes. H. gauthieri Coleman \& González, 2006

14. Body longer than breadth between tips of coxal plate IV spines

H. armata (Faxon, 1876)

Body broader than long ....... H. longispina González \& Coleman, 2002

\section{Acknowledgements}

We thank the following colleagues for the provision of specimens: Oliver Kroll, Christian Albrecht, Tom Wilke (Department of Animal Ecology and Systematics, Justus Liebig University Giessen; Germany), Geoff Boxshall (Department of Zoology, The Natural History Museum, London), Franck Bréhier 
(Alas, Balaguères; France) and Edmundo Moreno (Universidad Nacional del Altiplano, Puno; Perú). Miguel Alonso kindly assisted with fieldwork in the Altiplano. We also thank the editor and two anonymous reviewers for their helpful suggestions. This work was supported by the Spanish MINECO Grant CGL2016-76164-P, financed by the Agencia Española de Investigación (AEI) and the European Regional Development Fund (FEDER).

\section{Supplementary material}

Supplementary material is available online at: https://doi.org/10.6o84/mg.figshare.12023304

\section{References}

Adamowicz, S.J., Marinone, M.C., Menu-Marque, S., Martin, J.W., Allen, D.C., Pyle, M.N., De los Ríos, P., Sobel, C.N., Ibáñez, C., Pinto, J. \& Witt, J.D.S. (2018) The Hyalella (Crustacea: Amphipoda) species cloud of the ancient Lake Titicaca originated from multiple colonizations. Mol. Phylogenet. Evol., 125, 232-242.

Alcocer, J., Escobar, E., Lugo, A. \& Peralta, L. (1998) Littoral benthos of the saline crater lakes of the basin of Oriental, Mexico. Int. J. Salt Lake Res., 7, 87-108.

Alonso, M. \& Jaume, D. (2017) A new species of Hyalella from the High Andes of Ecuador (Crustacea, Amphipoda, Hyalellidae). ZooKeys, 686, 1-13.

Bauzà-Ribot, M.M., Jaume, D., Fornòs, J.J., Juan, C. \& Pons, J. (2011) Islands beneath islands: phylogeography of a groundwater amphipod crustacean in the Balearic archipelago. BMC Evol. Biol., 11, 221.

Baele, G., Li, W.L.S., Drummond, A.J., Suchard, M.A. \& Lemey, P. (2012) Accurate model selection of relaxed molecular clocks in Bayesian phylogenetics. Mol. Biol. Evol., 30, 239-243.
Baker, P.A. \& Fritz, S.C. (2015) Nature and causes of Quaternary climate variation of tropical South America. Quat. Sci. Rev., 124, 31-47.

Bollache, L., Kaldonski, N., Troussard, J.P., Lagrue, C. \& Rigaud, T. (2006) Spines and behaviour as defences against fish predators in an invasive freshwater amphipod. Anim. Behav., 72, 627-633.

Bousfield, E.L. (1996) A contribution to the reclassification of Neotropical freshwater Hyalellid amphipods (Crustacea: Gammaridea: Talitroidea). Boll. Mus. civ. Stor. Nat. Verona, 20, 175-224.

Brooks, J.L. (1950) Speciation in ancient lakes. Quart. Rev. Biol., 25, 131-176.

Bulycheva, A. (1957) The Sea Fleas of the USSR and Adjacent Waters (Amphipoda: Talitroidea). Keys to the Fauna of the USSR. Opred. po Faune SSSR, Akad. Nauk SSSR, 65, 1-185 (in Russian).

Carstens, B.C., Pelletier, T.A., Reid, N.M. \& Satler, J.D. (2013) How to fail at species delimitation. Mol. Ecol., 22, 4369-4383.

Chevreux, E. (1904) Mission G. de Créqui-Monfort et Sénéchal de la Grange. Note preliminaire sur les amphipodes recueillis par M. le Dr. NeveuLemaire dans le Lac Titicaca (Julliet, 1903). Bull. Soc. zool. Fr., 29, 131-134.

Chevreux, E. (1907) Mission Scientifique G. de Créqui-Monfort et Sénéchal de la Grange. Les amphipodes des lacs des hauts plateaux de l'Amérique du Sud. Extrait des Lacs Hauts Plateuaux de l'Amerique du Sud, 22 pp., figs. 30-41. Colburn, E.A. (1988) Factors influencing species diversity in saline waters of Death Valley, USA. Hydrobiologia, 158, 215-226.

Coleman, C.O. \& González, E.R. (2006) New Hyalellids (Crustacea, Amphipoda, Hyalellidae) from Lake Titicaca. Org. Divers. Evol., 6, Electr. Suppl. 10, 1-28.

Colgan, D., McLauchlan,, A., Wilson G., Livingston, S.P., Edgecombe, G., Macaranas, J.M., Cassis, G. \& Gray, M.R.V. (1998) Histone $\mathrm{H}_{3}$ and U2 snRNA DNA sequences and arthropod evolution. Aust. J. Zool., 46, 419-437. 
Copilaş-Ciocianu, D., Borza, P. \& Petrusek, A. (2020) Extensive variation in the morphological anti-predator defense mechanism of Gammarus roeselii Gervais, 1835 (Crustacea: Amphipoda). Freshw. Sci., 39. 47-55.

Costa, F.O., deWaard, J.R., Boutillier, J., Ratnasingham, S., Dooh, R.T., Hajibabaei, M. \& Hebert, P.D.N. (2007). Biological identifications through DNA barcodes: the case of the Crustacea. Can.J. Fish. Aquat. Sci., 64, 272-295.

Costa, F.O., Henzler, C.M., Lunt, D.H., Whiteley, N.M. \& Rock, J. (2009) Probing marine Gammarus (Amphipoda) taxonomy with DNA barcodes. Syst. Biodivers., 7, 365-379.

Crawford, G.I., Harrison, K., Lincoln, R. \& Boxshall, G.A. (1993) An introduction to the species flock of amphipods (Crustacea) of Lake Titicaca. Workshop Speciation in Ancient Lakes. Evolution, Biodiversity, Conservation. Scientific Station of the Hautes-Fagnes, Mont-Rigi, Robertsville, Belgium.

Cristescu, M.E., Adamowicz, S.J., Vaillant, J.J. \& Haffner, D.G. (2010) Ancient lakes revisited: from the ecology to the genetics of speciation. Mol. Ecol., 19, 4837-4851.

Cross, S.L., Baker, P.A., Seltzer, G.O., Fritz, S.C. \& Dunbar, R.B. (2001) Late Quaternary climate and hydrology of tropical South America inferred from an isotopic and chemical model of Lake Titicaca, Bolivia and Peru. Quaternary Res., 56, 1-9.

Daborn, G.R. (1976) Colonization of isolated aquatic habitats. Can. Field-Nat., 90, 56-57.

D’Agostino, K., Seltzer, G., Baker, P., Fritz, S.C. \& Dunbar, R. (2002) Late-Quaternary lowstands of Lake Titicaca: Evidence from high-resolution seismic data. Palaeogeogr. Palaeoclimatol. Palaeoecol., 179, 97-111.

Dejoux, C. (1992) The Amphipoda. In: C. Dejoux \& A. Iltis (Eds) Lake Titicaca: A Synthesis of Limnological Knowledge, pp. 346-356. Kluwer Academic Publishers, Dordrecht, The Netherlands.

Dejoux, C. (1993) Benthic invertebrates of some saline lakes of the Sud Lipez region, Bolivia. $H y$ drobiologia, 267, 257-267.
Drummond, A.J. \& Rambaut, A. (2007) BEAST: Bayesian evolutionary analysis by sampling trees. BMC Evol. Biol., 7, 214.

Egger, B., Koblmüller, S., Sturmbauer, C. \& Sefc, K.M. (2007) Nuclear and mitochondrial data reveal different evolutionary processes in the Lake Tanganyika cichlid genus Tropheus. BMC Evol. Biol., 7, 137.

Ezard, T., Fujisawa, T. \& Barraclough, T.G. (2009) Splits: SPecies' Limits by Threshold Statistics R package version 1.0-11/r29. http://R-Forge.Rproject.org/projects/splits/.

Faxon, W. (1876) Exploration of Lake Titicaca by Alexander Agassiz and S.W. Garman. IV. Crustacea. Bull. Mus. Comp. Zool., 3, 361-375.

Folmer, O., Black, M., Hoeh, W., Lutz, R. \& Vrijenhoek, R. (1994) DNA primers for amplification of mitochondrial cytochrome c oxidase subunit I from diverse metazoan invertebrates. Mol. Mar. Biol. Biotechnol., 3, 294-299.

Fornari, M., Risacher, F. \& Féraud, G. (2001) Dating of paleolakes in the central Altiplano of Bolivia. Palaeogeogr., Palaeoclimatol., Palaeoecol., 172, 269-282.

Fritz, S.C., Baker, P.A., Lowenstein, T.K., Seltzer, G.O., Rigsby, C.A., Dwyer, G.S., Tapia, P.M., Arnold, K.K., Ku, T.L. \& Lou, S. (2004) Hydrologic variation during the last 170,000 years in the southern hemisphere tropics of South America. Quaternary Res., 61, 95-104.

Fritz, S.C., Baker, P.A., Tapia, P., Spanbauer, T. \& Westover, K. (2012) Evolution of the Lake Titicaca basin and its diatom flora over the last $\sim 370,000$ years. Palaeogeogr., Palaeoclimatol., Palaeoecol., 317/318, 93-103.

Fryer, G. (1991) Comparative aspects of adaptative radiation and adaptation in Lake Baikal and the Great Rift lakes of Africa. Hydrobiologia, 211, 137-146.

Fryer, G. (1996) Endemism, speciation and adaptative radiation in ancient lakes. Environ. Biol. Fishes, 45, 109-131.

Fryer, G. (2000) Unanticipated diversity: The discovery and biological exploration of Africa's ancient lakes. Adv. Ecol. Res., 31, 1-16. Downloaded from Brill.com๑4/26/2023 12:17:22PM 
Fujisawa, T. \& Barraclough, T.G. (2013) Delimiting species using single-locus data and the Generalized Mixed Yule Coalescent approach: a revised method and evaluation on simulated data sets. Syst. Biol., 62, 707-724.

Galat, D.L., Coleman, M. \& Robinson, R. (1988) Experimental effects of elevated salinity on three benthic invertebrates in Pyramid Lake, Nevada. Hydrobiologia, 158, 133-144.

González, E.R. \& Coleman, C.O. (2002) Hyalella armata (Crustacea, Amphipoda, Hyalellidae) and the description of a related new species from Lake Titicaca. Org. Divers. Evol., 2, 261-262.

González, E.R. \& Watling, L. (2001) Three new species of Hyalella from Chile (Crustacea: Amphipoda: Hyalellidae). Hydrobiologia, 464, 175-199. González, E.R. \& Watling, L. (2003) Two new species of Hyalella from Lake Titicaca, and redescriptions of four others in the genus (Crustacea: Amphipoda). Hydrobiologia, 497, 181-204.

Gorthner, A. (1994) What is an ancient lake? Arch. Hydrobiol. Beihefte Ergebnisse Limnol., 44, 97-100.

Gouy, M., Guindon, S. \& Gascuel, O. (2009) SeaView version 4: a multiplatform graphical user interface for sequence alignment and phylogenetic tree building. Mol. Biol. Evol., 27, 221-224.

Hammer, U.T., Sheard, J.S. \& Kranabetter, J. (1990) Distribution and abundance of littoral benthic fauna in Canadian prairie saline lakes. Hydrobiologia, 197, 173-192.

Hendrich, L., Pons, J., Ribera, I. \& Balke, M. (2010) Mitochondrial Coxı sequence data reliably uncover patterns of insect diversity but suffer from high lineage- idiosyncratic error rates. PLOS ONE, 5, e14448.

Hoffman, J. (2006) Adaptative radiation of Hyalella (Crustacea, Amphipoda) in Lake Titicaca. The Hyalella longipes-lucifugax-complex - A taxonomical case study. In: A. Kossler, R. Kohring \& F. Riedel (Eds) International Symposium "Speciation in Ancient Lakes, SIAL IV", Berlin, September 4-8, 2006. Abstracts. Berliner Paläobiologische Abhandlungen, 9. $70 \mathrm{pp}$.
Horton, T., Lowry, J., De Broyer, C., Bellan-Santini, D., Coleman, C.O., Corbari, L., Costello, M.J., Daneliya, M., Dauvin, J.C., Fišer, C., Gasca, R., Grabowski, M., Guerra-García, J.M., Hendrycks, E., Hughes, L., Jaume, D., Jazdzewski, K., Kim, Y.H., King, R., Krapp-Schickel, T., LeCroy, S., Lörz, A.N., Mamos, T., Senna, A.R., Serejo, C., Sket, B., Souza-Filho, J.F., Tandberg, A.H., Thomas, J.D., Thurston, M., Vader, W., Väinölä, R., Vonk, R., White, K. \& Zeidler, W. (2019) World Amphipoda Database. Hyalella S. I. Smith, 1874. Accessed through: World Register of Marine Species at: http://marinespecies.org/aphia.php?p= taxdetails\&id $=158104$ on 2019-07-03.

Jażdżewska, A.M. \& Mamos, T. (2019) High species richness of Northwest Pacific deep-sea amphipods revealed through DNA barcoding. Prog. Oceanogr.,178, 102184.

Kahle, D. \& Wickham, H. (2013) ggmap: Spatial Visualization with ggplot2. $R J .$, 5, 144-161.

Kamaltynov, R.M. (1999) On the higher classification of Lake Baikal amphipods. Crustaceana, 72, 933-944.

Kapli, P., Lutteropp, S., Zhang, J., Kobert, K., Pavlidis, P., Stamatakis, A. \& Flouri, T. (2017) Multirate Poisson tree processes for single-locus species delimitation under maximum likelihood and Markov chain Monte Carlo. Bioinformatics, $33,1630-1638$.

Kar, N., Garzione, C., Jaramillo, C., Shanahan, T., Carlotto, V., Pullena, A., Moreno, F., Anderson, V., Moreno, E. \& Eiler, J. (2016) Rapid regional surface uplift of the northern Altiplano plateau revealed by multiproxy paleoclimate reconstruction. Earth Planet. Sci. Lett., 447, 33-47.

Katoh, K. \& Standley, D.M. (2013) MAFFT multiple sequence alignment software version 7 : improvements in performance and usability. Mol. Biol. Evol., 30, 772-780.

Kekkonen, M., Mutanen, M., Kaila, L., Nieminen, M. \& Hebert, P.D.N. (2015) Delineating species with DNA barcodes: a case of taxon dependent method performance in moths. PLoS One, 10, e0122481. 
Koblmüller, S., Nevado, B., Makasa, L., van Steenberge, M., Vanhove, M.P.M., Verheyen,, E., Sturmbauer C. \& Sefc, K.M. (2017) Phylogeny and phylogeography of Altolamprologus: ancient introgression and recent divergence in a rock-dwelling Lake Tanganyika cichlid genus. Hydrobiologia, 791, 35-50.

Kocher, T.D. (2004) Adaptive evolution and explosive speciation: the cichlid fish model. Nat. Rev. Genet., 5, 288.

Kroll, O., Hershler, R., Albrecht, C., Terrazas, E.M., Apaza, R., Fuentealba, C., Wolff, C. \& Wilke, T. (2012) The endemic gastropod fauna of Lake Titicaca: correlation between molecular evolution and hydrographic history. Ecol. Evol., 2, 1517-1530.

Lanfear, R., Calcott, B., Ho, S.Y. \& Guindon, S. (2012) PartitionFinder: combined selection of partitioning schemes and substitution models for phylogenetic analyses. Mol. Biol. Evol., 29, 1695-1701.

Lauzanne, L. (1992) Native species. The Orestias. In: C. Dejoux \& A. Iltis (Eds) Lake Titicaca: A Synthesis of Limnological Knowledge, pp. 405419. Kluwer Academic Publishers, Dordrecht, The Netherlands.

Macdonald III, K.S., Yampolsky, L. \& Duffy, J.E. (2005) Molecular and morphological evolution of the amphipod radiation of Lake Baikal. Mol. Phyl. Evol., 35, 323-343.

Meier, J. I., Stelkens, R.B., Joyce, D.A., Mwaiko, S., Phiri, N., Schliewen, U.K., Selz, O.M., Wagner, C.E., Katongo, C. \& Seehausen, O. (2019) The coincidence of ecological opportunity with hybridization explains rapid adaptive radiation in Lake Mweru cichlid fishes. Nat. Commun., 10, 1-11.

Meyer, A., Kocher, T.D., Basasibwaki, P. \& Wilson, A.C. (1990) Monophyletic origin of Lake Victoria cichlid fishes suggested by mitochondrial DNA sequences. Nature, 347, 550553 .

Monaghan, M.T., Balke, M., Pons, J. \& Vogler, A.P. (2006) Beyond barcodes: Complex DNA taxonomy of a South Pacific island radiation. Proc. R. Soc. B-Biol. Sci., 273, 887-893.

Naumenko, S.A., Logacheva, M.D., Popova, N.V., Klepikova, A.V., Penin, A.A., Bazykin, G.A., Etingova, A.E., Mugue, N.S., Kondrashov, A.S. \& Yampolsky, L.Y. (2017) Transcriptome-based phylogeny of endemic Lake Baikal amphipod species flock: fast speciation accompanied byfrequent episodes of positive selection. Mol. Ecol., 26, 536-553.

Nevado, B., Koblmüller, S., Sturmbauer, C., Snoeks, J., Usano-Alemany, J. \& Verheyen, E. (2009) Complete mitochondrial DNA replacement in a Lake Tanganyika cichlid fish. Mol. Ecol., 18, 4240-4255.

Nguyen, L.T., Schmidt, H.A., von Haeseler, A. \& Minh, B.Q. (2014) IQ-TREE: a fast and effective stochastic algorithm for estimating maximumlikelihood phylogenies. Mol. Biol. Evol., 32, 268-274.

Nunnery, J.A., Fritz, S.C., Baker, P.A. \& Salenbien, W. (2019) Lake-level variability in Salar de Coipasa, Bolivia during the past $\sim 40,000$ yr. Quaternary Res., 91, 881-891.

Pons, J., Barraclough, T.G., Gómez-Zurita, J., Cardoso, A., Duran, D.P., Hazell, S., Kamoun, S., Sumlin, W.D. \& Vogler, A.P. (2006) Sequencebased species delimitation for the DNA taxonomy of undescribed insects. Syst. Biol., 55, 595609.

Puillandre, N., Lambert, A., Brouillet, S. \& Achaz, G. (2012) ABGD, Automatic Barcode Gap Discovery for primary species delimitation. Mol. Ecol., 21, 1864-1877.

Rambaut, A., Drummond, A.J., Xie, D., Baele, G. \& Suchard, M.A. (2018) Posterior summarization in Bayesian phylogenetics using Tracer 1.7. Syst. Biol., 67, 901-904.

Rosine, W.N. (1956) On the transport of the common amphipod, Hyalella azteca, in South Dakota by the mallard duck. Proc. S. Dak. Acad. Sci., 35, 203.

Sars, G.O. (1894) Crustacea Caspia. Contributions to the knowledge of the carcinological fauna of 
the Caspian Sea. Part III. Amphipoda. Supplement. Bull. Acad. Imp. Sci. Saint Pétersbourg. Octubre. Tome I, 179-242.

Sars, G.O. (1896) Crustacea Caspia. Contributions to the knowledge of the carcinological fauna of the Caspian Sea. Amphipoda. Gammaridae (part). Bull. Acad. Imp. Sci. Saint Pétersbourg. Mai. Tome IV, 421-516.

Sket, B. (200o) Fuxiana yangi g.n., sp.n. (Crustacea: Amphipoda), a "Baikaloid" amphipod from the depths of Fuxian Hu, an ancient lake in the karst of Yunnan, China. Arch. Hydrobiol., 147, 241-255.

Smith, S.I. (1874) The Crustacea of the freshwaters of the United States. A synopsis of the higher freshwater Crustacea of the Northern United States, Appendix F. Natural History. Report of the Commissioner for 1872 and 1873 . United States Commission of Fish and Fisheries, 2, 637-661.

Swanson, G.A. (1984) Dissemination of amphipods by waterfowl.J. Wildlife Manage., 48, 988-991.

Takahashi, T. \& Moreno, E. (2015) A RAD-based phylogenetics for Orestias fishes from Lake Titicaca. Mol. Phylogenet. Evol., 93, 307-317.

Takebayashi, N. (2015) uniqHaplo.pl. Available via http://raven.iab.alaska.edu/ ntakebay/teaching/programming/perl-scripts/perl-scripts .html.

Takhteev, V.V. (200o) Trends in the evolution of Baikal amphipods and evolutionary parallels with some marine Malacostracan faunas. $A d v$. Ecol. Res., 31, 197-220.

Takhteev, V.V. (2019) On the current state of taxonomy of the Baikal Lake amphipods (Crustacea: Amphipoda) and the typological ways of constructing their system. Arthropoda Selecta, 28, 374-402.

Talavera, G., Dincă, V. \& Vila, R. (2013) Factors affecting species delimitations with the GMYC model: insights from a butterfly survey. Methods Ecol. Evol. 4, 1101-1110.

Tempestini, A., Rysgaard, S. \& Dufresne, F. (2018) Species identification and connectivity of marine amphipods in Canada's three oceans. PLoS One, 13, e0197174.

Väinölä, R., Witt, J.D.S., Grabowski, M., Bradbury, J.H., Jazdzewski, K. \& Sket, B. (2008) Global diversity of amphipods (Amphipoda; Crustacea) in freshwater. Hydrobiologia, 595, 241-255.

Vermeij, G.J. \& Covich, A.P. (1978) Coevolution of freshwater gastropods and their predators. Amer. Naturalist., 112, 833-843.

Wagner, C.E., Harmon, L.J. \& Seehausen, O. (2012) Ecological opportunity and sexual selection together predict adaptive radiation. Nature, 487 , 366-369.

West, K. \& Cohen, A. (1996) Shell microstructure of gastropods from Lake Tanganyika, Africa: adaptation, convergent evolution, and escalation. Evolution, 50, 672-681.

Weckel, A.L. (1910) Freshwater amphipods from Peru. Proc. U.S. Nat. Mus., 38, 623-624.

Wolff, C., Albrecht, C. \& Wilke, T. (2019) Recovery from interglacial-related bottleneck likely triggered diversification of Lake Titicaca gastropod species flock. J. Great Lakes Res., in press. doi:10.1016/j.jglr.2019.08.0o6

RECEIVED: 9 SEPTEMBER 2019 | REVISED AND

ACCEPTED: 20 MARCH 2020

EDITOR: D. COPILAS-CIOCIANU 